Note

\title{
In vitro detection and primary cultivation of bacteria producing materials inhibitory to ruminal methanogens ${ }^{\text {负 }}$
}

\author{
Rosalind A. Gilbert *, Diane Ouwerkerk, Li Hua Zhang, Athol V. Klieve ${ }^{1}$ \\ and Cooperative Research Centre for Beef Genetic Technologies
}

Animal Research Institute, Queensland Primary Industries and Fisheries, Yeerongpilly, Queensland, 4105, Australia

\section{A R T I C L E I N F O}

\section{Article history:}

Received 30 September 2009

Received in revised form 3 December 2009

Accepted 4 December 2009

Available online 11 December 2009

\section{Keywords:}

Rumen

Methanogen

Archaea

Growth inhibition

\begin{abstract}
A B S T R A C T
A novel method for screening bacterial isolates for their potential to inhibit the growth of ruminal methanogenic Archaea was developed using a modification of the soft agar overlay technique, formally used for the isolation of lytic bacteriophages. This method may be used in the specific, hydrogen-rich conditions required for the growth of ruminal methanogenic Archaea.
\end{abstract}

Crown Copyright @ 2009 Published by Elsevier B.V. All rights reserved.
As global attention becomes focused on reducing atmospheric methane emissions produced by ruminant livestock, strategies for controlling the amount of methane produced during rumen fermentation are being developed. One approach that may be used to reduce ruminant methane production involves identifying products able to inhibit the growth of methanogenic Archaea (Klieve and Hegarty, 1999). Archaeal strains have been shown to be the source of most of the methane produced by ruminants as they metabolize the hydrogen pool normally produced as a byproduct of rumen fermentation (McAllister and Newbold, 2008). Despite diverse populations of Archaea being found in the rumen (Janssen and Kirs, 2008), rumen Archaea have often proven to be difficult to grow and maintain in vitro. Traditional methods used for screening potential inhibitors of these Archaea need to be modified and optimized for these organisms.

Previous studies to identify potential inhibitors of Archaea, described as archaeocins (O'Connor and Shand, 2002), have been developed for haloarchaea and hyperthermophilic Crenarchaeota, which require elevated salt concentrations or increased temperatures respectively. In contrast, rumen methanogenic Archaea have often been cultivated in anaerobic growth medium containing high concentrations of rumen fluid with either the inclusion of sodium

\footnotetext{
is Crown Copyright, The State of Queensland (through the Department of Employment, Economic Development and Innovation).

* Corresponding author. Tel.: +61 73362 9616; fax: +61 733629530.

E-mail address: ros.gilbert@deedi.qld.gov.au (R.A. Gilbert).

${ }^{1}$ Current address: School of Animal Studies, University of Queensland, Gatton Campus, Gatton, Queensland, Australia.
}

formate, or use of a gaseous headspace of $\mathrm{H}_{2} / \mathrm{CO}_{2}$ (Joblin, 2005). Archaea may be initially isolated from rumen fluid samples on solid media within Hungate roll tubes (Miller et al., 1986). However, to our knowledge, there are no published reports of routine culture of rumen Archaea on solid media in Petri dishes. Confluent growth on solid media would be preferred in order to identify potential growth inhibitors and measure zones of inhibition. The method described in this study involved modifying the soft agar overlay technique of Gratia (1936), as described by Adams (1959).

To maintain anaerobic conditions all culture manipulations were undertaken in an anaerobic chamber (Coy Laboratory Products Inc. Ann Arbor, Michigan) using anaerobic procedures and culture techniques routinely utilized for rumen microbiology (Hungate, 1969; Holdeman et al., 1977). Strains of methanogenic Archaea isolated in our laboratory and employed in the screening method included Methanobrevibacter isolates of bovine origin, designated YE 301 and YE 304 and a bovine isolate of Methanobacterium bryantii, designated YE 299 (strains described in Table 1). Methanobrevibacter ruminantium strain ATCC 35063 was also employed in the screening method. All strains were cultured in screw-top Hungate tubes (Bellco Glass Inc., NJ, USA) containing $9.6 \mathrm{~mL}$ volumes of BY medium prepared under an $\mathrm{O}_{2}$-free $\mathrm{CO}_{2}$ atmosphere and supplemented after autoclaving with $0.1 \mathrm{~mL}$ vitamin $\mathrm{mix}, 0.1 \mathrm{~mL}$ Penicillin/Streptomycin solution (12 $\mathrm{mg} \mathrm{mL}^{-1}$ and $2 \mathrm{mg} \mathrm{mL}^{-1}$ ) and $0.1 \mathrm{~mL}$ Vancomycin solution ( $2 \mathrm{mg} \mathrm{mL}^{-1}$ ) (media and supplements as described by Joblin, 2005). All subcultures involved the transfer of $0.2 \mathrm{~mL}$ volumes of culture to fresh media under anaerobic conditions. Once inoculated, the headspace of the hungate tubes was pressurized with $\mathrm{H}_{2}$ gas to 
Table 1

Description of Archaeal strains employed.

\begin{tabular}{ll}
\hline Archaeal isolate & GenBank blast similarity \\
\hline Methanobrevibacter sp. isolate & $98 \%$ similarity (914/930 bp) to \\
YE 301 (GQ906575) & Methanbrevibacter smithii ATCC 35061 \\
Methanobrevibacter sp. isolate & $98 \%$ similarity (914/930 bp) to \\
YE 304 (GQ906576) & Methanbrevibacter smithii ATCC 35061 \\
Methanobacterium bryantii isolate & $99 \%$ similarity (931/934 bp) to \\
YE 299 (GQ906568) & Methanobacterium bryantii DSM 863 \\
\hline
\end{tabular}

approximately $207 \mathrm{kPa}$ and incubated with rocking on a platform mixer (Ratek Instruments, Boronia, Victoria, Australia) at $39^{\circ} \mathrm{C}$, for 3 to 4 days.

The soft agar overlay method first involved the preparation of an agar base-plate to act as a support matrix and allow growth of bacterial isolates obtained from environmental samples. Initial studies used bovine rumen fluid as a source of bacteria that may show inhibitory activity, due to the distinct likelihood of antimicrobial activity against methanogenic Archaea naturally occurring in the highly competitive microbial community present within the rumen. The base-plate was prepared by adding to $90 \mathrm{~mm}$ diameter Petri dishes approximately $12 \mathrm{~mL}$ molten $\left(50-55^{\circ} \mathrm{C}\right)$ BY agar $(1.2 \%[\mathrm{w} / \mathrm{v}]$ agar, Oxoid) modified to include $0.2 \%(\mathrm{w} / \mathrm{v})$ glucose and $0.2 \%(\mathrm{w} / \mathrm{v})$ cellobiose. Rumen fluid samples were collected from a single steer (2 year old Brahman-cross) free-ranging on a diet of native pasture (Animal ethics approval number SA 2008/07/254). A series of dilutions in ten-fold increments, from $10^{-1}$ to $10^{-9}$, were prepared of the rumen fluid, using anaerobic dilution solution (described by McSweeney et al., 2005, modified by substituting resazurin for indigo carmine) and $100 \mu \mathrm{L}$ subsamples were spread onto the prepared base plates. Plates were then sealed in a polycarbonate anaerobic jar (BBL Gas pak system, Becton Dickinson), which was then removed from the anaerobic chamber and incubated at $39{ }^{\circ} \mathrm{C}$ for $24 \mathrm{~h}$. Plated dilutions with easily distinguishable colonies (usually less than 30 colony forming units) were then overlayed with soft agar.

For preparation of each soft agar overlay, a single $4 \mathrm{~d}, 10 \mathrm{~mL}$ culture of methanogen (described above) was opened in the anaerobic chamber and poured into a sterile disposable $15 \mathrm{~mL}$ volume tube (Falcon). This tube was then taken from the anaerobic chamber and cells pelleted by centrifugation at $600 \times g$ for $5 \mathrm{~min}$. The tube was then transferred back into the anaerobic chamber and the supernatant removed. The cell pellet was gently resuspended in $500 \mu \mathrm{L}$ BY medium. A $4.5 \mathrm{~mL}$ volume of molten BY medium containing $0.7 \%$ agar supplemented with vitamin mix immediately prior to use, was then added to the cell suspension and quickly poured evenly over the bacterial colonies on the base plate.

Soft agar overlay plates were allowed to set for $30 \mathrm{~min}$ at room temperature, inverted and transferred into a steel anaerobic canister of a design similar to those described by Sowers and Noll (1995). An additional Petri dish containing $\mathrm{CaCl}_{2}$ pellets $(-4+30$ mesh, Sigma Aldrich) as a desiccant, was also included in the canister. The canister was then sealed, transferred out of the anaerobic chamber, pressurized with hydrogen gas to greater than atmospheric pressure $(80 \mathrm{kPa})$ and incubated at $39^{\circ} \mathrm{C}$ for $6 \mathrm{~d}$. Inhibition zones produced by bacterial colonies were readily visible for the four strains of Archaea listed above (an example shown in Fig. 1), and colony and zone dimensions could be measured. Colonies of each rumen isolate causing the inhibition were removed from the agar plate by taking an agar plug from the plate using a wide bore micropipette tip. This agar plug was transferred into anaerobic BY broth modified to include $0.2 \%(\mathrm{w} / \mathrm{v})$ glucose and $0.2 \%(\mathrm{w} / \mathrm{v})$ cellobiose and incubated at $39{ }^{\circ} \mathrm{C}$ for $24 \mathrm{~h}$. The production of inhibition zones was confirmed by repeating the soft agar overlay procedure using colonies of the isolate on the base plate and a soft agar overlay of methanogenic Archaea.

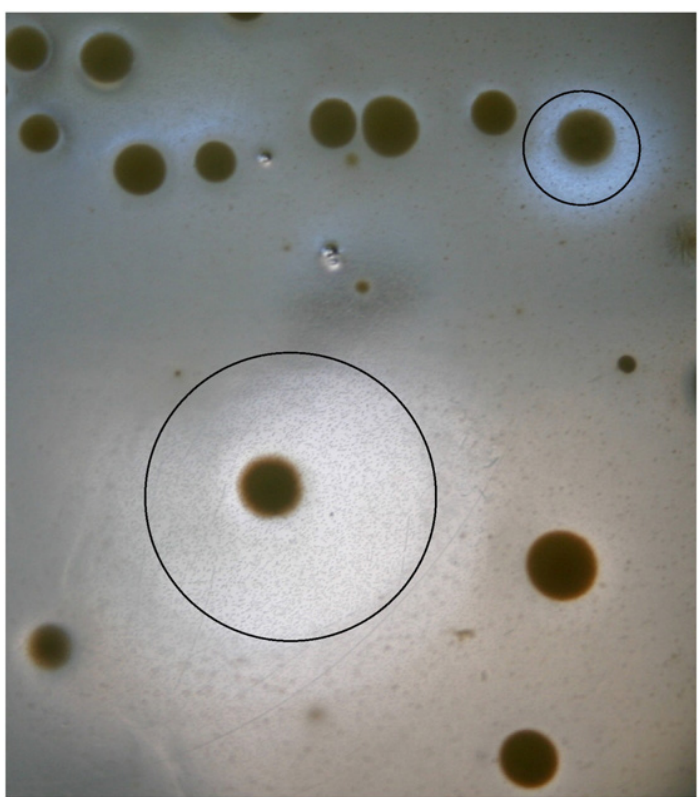

Fig. 1. A confluent layer of the methanogenic Archaea, Methanobrevibacter strain YE 304, displaying inhibition zones (highlighted with circles) caused by the underlying bacterial colonies, isolated from bovine rumen fluid.

The method addresses some of the technical difficulties encountered when growing methanogenic Archaea in solid media and allows both the visualization of inhibition zones, and the subsequent isolation of bacterial strains producing inhibitory compounds. This method is a very useful tool for screening large numbers of uncharacterized bacteria which may be sourced from a wide variety of anaerobic environments, as potential inhibitors of ruminal methanogenic Archaea.

\section{Acknowledgments}

We wish to thank Anita Maguire for the technical assistance and Jim Kidd for supplying rumen fluid samples. This work was co-funded by the Cooperative Research Center for Beef Genetic Technologies.

\section{References}

Adams, M.H., 1959. Bacteriophages. Interscience Publishers Inc., New York.

Gratia, A., 1936. Des relations numeriques entre bacteries lysogenes et particules des bacteriophages. Ann. Inst. Pasteur. 57, 652-676.

Holdeman, L.V., Cato, E.P., Moore, W.E.C., 1977. Anaerobe Laboratory Manual, 4th ed Virginia Polytechnic Institute and State University, Blacksburg.

Hungate, R.E., 1969. A roll tube method for the cultivation of strict anaerobes. In: Norris, J.R., Ribbons, D.W. (Eds.), Methods in Microbiology. Academic Press, London, pp. 117-135.

Janssen, P.H., Kirs, M., 2008. Minireview: structure of the archaeal community of the rumen. Appl. Environ. Microbiol. 74, 3619-3625.

Joblin, K.N., 2005. Methanogenic archaea. In: Makkar, H.P.S., McSweeney, C.S. (Eds.) Methods in Gut Microbiology for Ruminants. Part 2. Springer, Netherlands, pp. 47-53.

Klieve, A.V., Hegarty, R.S., 1999. Opportunities for biological control of ruminal methanogenesis. Aust. J. Agric. Res. 50, 1315-1319.

McAllister, T.A., Newbold, C.J., 2008. Redirecting rumen fermentation to reduce methanogenesis. Aust. J. Exp. Agric. 48, 7-13.

McSweeney, C.S., Denman, S.E., Mackie, R.I., 2005. Rumen bacteria. In: Makkar, H.P.S McSweeney, C.S. (Eds.), Methods in Gut Microbiology for Ruminants. Part 2 Springer, Netherlands, pp. 23-37.

Miller, T.L., Wolin, M.J., Hongxue, Z., Bryant, M.P., 1986. Characteristics of methanogens isolated from bovine rumen. Appl. Environ. Microbiol. 51, 201-202.

O'Connor, E.M., Shand, R.F., 2002. Halocins and sulfolobicins: the emerging story of archaeal protein and peptide antibiotics. J. Ind. Microbiol. Biotech. 28, 23-31.

Sowers, K.R., Noll, K.M., 1995. Techniques for anaerobic growth. In: Sowers, K.R Schreier, H.J. (Eds.), Archaea a Laboratory Manual, Methanogens. Cold Spring Harbor Laboratory Press, New York, pp. 15-47. 